\title{
VITAMIN D REQUIREMENT IN PREGNANCY TO MAINTAIN SUFFICIENT VITAMIN IN NEWBORN A RANDOMIZED TRIAL
}

\author{
M. Shakiba
}

Shahid Sadoghee University, Yazd, Iran

Introduction: Vitamin D requirement concept was changed in recent years, pregnancy and intra uterine life is a crucial period of life for development and we do not know exact amount of vitamin requirement in that. This study is a randomized trial to find doses of vitamin D in pregnancy to make sufficient level in newborn.

Material and method: In 2009 at Yazd in center of Iran on 52 healthy pregnant women this study was performed, they randomly received 50,000 or 100,000 IU vitamin D3/month from second trimester and 17 others treated first as deficiency with 200,000 IU vitamin D3 then 50,000IU/month. 25-OH vitamin D in cord blood was check by chemiluminescence immunoassay and level more than $20 \mathrm{ng} / \mathrm{ml}$ accepted as sufficient.

Result: All mothers had vitamin level below $30 \mathrm{ng} / \mathrm{ml}$ at first trimester, $24 \%$ of mothers on $50,000 /$ month(about2000IU/day ) could not achieve sufficient level in newborns. All in other two group had level more than 20ng.ml in their babies. we could not find any side effect during consumption.

Conclusion: In area with high prevalence of vitamin D deficiency in mothers about 4000IU /day vitamin D3 from second trimester of pregnancy is needed to make level more than $20 \mathrm{ng} / \mathrm{ml}$ of $25-\mathrm{OH}$ vitamin D in newborn, consuming less than $2000 \mathrm{IU}$ /day is not sufficient in all. 